\section{Reactive arthritis, a missing link: comment on the recent article from Sepriano et al}

The recent paper from Sepriano et al provides an extremely important new insight on the concept of axial spondyloarthritis (axSpA). ${ }^{1}$ Clearly, the Gestalt of axSpA is heterogeneous, with three recognisable clinical entities labelled as: 'pure axial SpA', 'axial SpA with peripheral signs' and 'axial SpA at risk'. The finding given in the paper suggests a larger overlap between axSpA and pSpA than anticipated at the time when the Assessment of SpondyloArthritis international Society (ASAS) criteria were developed. Thus, the question arises as to how accurately the three recognisable clinical entities of the ASAS classification criteria represent the diseases entities originally lumped together in the historical concept of SpA.

The unifying historical concept of SpA lumps together an interrelated yet heterogeneous group of disorders which includes ankylosing spondylitis (AS), psoriatic arthritis, arthropathy of inflammatory bowel diseases (ulcerative colitis and Crohn's disease), reactive arthritis (ReA), undifferentiated $\mathrm{SpA}$ and juvenile SpA. ${ }^{2} \mathrm{ReA}$ is characterised by preceding infections of the urogenital, gastrointestinal and respiratory tract, and these are best explored for Chlamydia trachomatis and Chlamydia pneumoniae infections for the joint and spine manifestations. ${ }^{3}$ Preceding infection of urethritis/cervicitis or diarrhoea within 1 month prior to the onset of arthritis/enthesitis/dactylitis is included in the ASAS criteria for peripheral SpA but not in those for axial SpA. Baseline patient characteristics and the final latent class analysis models in the SPondyloArthritis Caught Early (SPACE) and DEvenir des Spondylarthopathies Indifférenciées Récentes (DESIR) cohorts do not mention preceding infections. ${ }^{1}$ Thus, the latent class and transition analyses neglect infections, although ReA typically manifests with peripheral arthritis as well as enthesitis, tendinitis, bursitis and inflammatory low back pain. ${ }^{4}$ Moreover, remitting and chronic ReA may evolve into sacroiliitis in $14 \%-49 \%$, and into AS in $12 \%-26 \%$ of patients, depending on the triggering infection; a minority of patients even manifest radiological sacroiliitis during the first known attack or arthritis (compare ref 5). Importantly, the causative infections are often asymptomatic or mild, or they may precede the arthritis by several years. Therefore, these silent infections may not appear in medical history and are only discovered by targeted investigation, such as has been demonstrated, for example, for C. trachomatis and C. pneumoniae (compare ref 6).

Diseases are defined and categorised in a variety of ways: by the symptoms with which they present (syndromic), their underlying causes (aetiological), the biological mechanisms involved (pathogenic), available treatments, historical precedent and through diagnostic exclusion. ${ }^{7}$ Understanding gut microbiotahost genetic relationships may contribute to clarification of the pathogenesis of postinfectious SpA and pave the way from symptomatic to aetiological classification. ${ }^{8}$ Of note, in the study from a geographic region with a high prevalence of ReA (Guatemala), prospectively included adult subjects with preceding infections developing arthritis classified as $\mathrm{pSpA}$, and control subjects not developing arthritis, both had radiographic sacroiliitis in 56\% and $50 \%$ of individuals, respectively; thus the postinfectious
pSpA would presumably meet the Gestalt of 'axial SpA with peripheral signs, ${ }^{8}$

In conclusion, in recent years the ASAS classification criteria for axial SpA have provided an important contribution to education, research and clinical trials addressing earlier diagnosis, outcome measurements and new treatments for axial SpA. Nonetheless, future classification sets which specify relevant infectious triggers should be useful in advancing classification and related treatment studies, thus giving increased validity also for geographic regions outside Europe which display a higher prevalence of ReA.

\section{Henning Zeidler $\odot,{ }^{1}$ Alan P Hudson ${ }^{2}$}

${ }^{1}$ Internal Medicine, Immunology and Rheumatology, Medizinische Hochschule, Hannover, Germany

${ }^{2}$ Immunology and Microbiology, Wayne State University School of Medicine, Detroit, Michigan, USA

Correspondence to Professor Henning Zeidler, Internal Medicine, Immunology and Rheumatology, Medizinische Hochschule, Hannover 30625, Germany;

Zeidler.Henning@mh-hannover.de

Contributors $\mathrm{HZ}$ wrote the first draft of the manuscript. $\mathrm{HZ}$ and APH reviewed the draft version and approved the final manuscript.

Funding The authors have not declared a specific grant for this research from any funding agency in the public, commercial or not-for-profit sectors.

Competing interests None declared.

Patient and public involvement Patients and/or the public were not involved in the design, or conduct, or reporting, or dissemination plans of this research.

Patient consent for publication Not required.

Provenance and peer review Not commissioned; internally peer reviewed.

(c) Author(s) (or their employer(s)) 2020. No commercial re-use. See rights and permissions. Published by BMJ.

$$
\text { Check for updates }
$$

To cite Zeidler H, Hudson AP. Ann Rheum Dis Epub ahead of print: [please include Day Month Year]. doi:10.1136/annrheumdis-2020-217326

Received 12 March 2020

Accepted 14 March 2020

Ann Rheum Dis 2020;0:1. doi:10.1136/annrheumdis-2020-217326

\section{ORCID iD}

Henning Zeidler http://orcid.org/0000-0001-6354-6949

\section{REFERENCES}

1 Sepriano A, Ramiro S, van der Heijde D, et al. What is axial spondyloarthritis? A latent class and transition analysis in the SPACE and DESIR cohorts. Ann Rheum Dis 2020;79:324-31.

2 Zeidler $\mathrm{H}$, Amor B. The assessment in spondyloarthritis International Society (ASAS) classification criteria for peripheral spondyloarthritis and for spondyloarthritis in general: the spondyloarthritis concept in progress. Ann Rheum Dis 2011;70:1-3.

3 Carter JD, Hudson AP. Recent advances and future directions in understanding and treating Chlamydia- induced reactive arthritis. Expert Rev Clin Immunol 2017;13:197-206.

4 Hannu T. Reactive arthritis. Best Pract Res Clin Rheumatol 2011;25:347-57.

5 Leirisalo-Repo M, Sieper J. Reactive arthritis: epidemiology, clinical features, and treatment. In: Weisman MH, van der Heijde D, Reveille JD, eds. Ankylosing spondylitis and the spondyloarthropathies. Philadelphia: Mosby Elsevier, 2006: 53-64.

6 Zeidler H, Hudson AP. New insights into Chlamydia and arthritis. Promise of a cure? Ann Rheum Dis 2014;73:637-44.

7 Livingstone-Banks J. The case for a meta-nosological investigation of pragmatic disease definition and classification. J Eval Clin Pract 2018;24:1013-8.

8 Manasson J, Shen N, Garcia Ferrer HR, et al. Gut microbiota perturbations in reactive arthritis and postinfectious spondyloarthritis. Arthritis Rheum 2018;70:242-54. 